Western University

Scholarship@Western

Psychology

Psychology

$12-1-2011$

\title{
Perceived parental attachment and achievement motivation
}

\author{
Mena Bal \\ Imants Barušs \\ King's University College, baruss@uwo.ca
}

Follow this and additional works at: https://ir.lib.uwo.ca/kingspsychologypub

Part of the Psychology Commons

Citation of this paper:

Bal, Mena and Barušs, Imants, "Perceived parental attachment and achievement motivation" (2011). Psychology. 6. https://ir.lib.uwo.ca/kingspsychologypub/6 


\title{
PERCEIVED PARENTAL ATTACHMENT AND ACHIEVEMENT MOTIVATION ${ }^{1,2}$
}

\author{
M. BAL \\ Niagara University, Ontario, Canada \\ IMANTS BARUŠS \\ Department of Psychology
}

King's University College at the University of Western Ontario

London, Ontario, Canada

(C) 2011 Mena Bal and Imants Barušs

\footnotetext{
${ }^{1}$ Address correspondence to Professor Imants Barušs, Department of Psychology, King's University College at the University of Western Ontario, 266 Epworth Ave., London, Ontario, N6A 2M3, Canada (baruss@uwo.ca).

2 This report is based on an undergraduate thesis in psychology written by the first author and supervised by the second. The authors thank Wendy Ellis for assistance with the design of this study, Shannon Foskett for editing and preparing the manuscript, Chris Roney for contributing information about motivation, and King's University College for research funds.
} 
Summary.-A significant amount of research in attachment theory has been devoted to factors affecting academic achievement, but less attention has been given to the role of attachment in the relation between academic achievement and achievement motivation. The current preliminary study examined the role of perceived parental attachment on achievement motivation. Self-report data obtained from the Parental Attachment Questionnaire, Achievement Goals Questionnaire, and the Performance Failure Appraisal Inventory were collected from 50 university students with a mean age of $18.8 \mathrm{yr}$. Correlation and regression analyses indicated that parental facilitation of independence correlated significantly and negatively with fear of failure. Results yielded partial support for the hypothesis that performance-oriented goals are related to a fear of failure, whereas mastery-oriented goals are not. These results also suggest that high parental attachment in the case of high-frequency religious practitioners is related to an increased chance of acquiring a more avoidance-oriented achievement motivation. 
Much research in attachment theory (Bowlby, 1982) has focused on the effects of attachment style on social interactions (Vicary \& Fraley, 2007; Kieffer \& Briggs 2002), but less focus has been given to the role of attachment in relation to academic performance. Dai, Moon and Feldhusen (1998) suggested that goal theories are important when understanding the achievement motivation of students. Studies in achievement goal theory (Jagacinski \& Duda, 2001) have theorized that performance goals rooted in a motive to compete with others may be harmful to students' intrinsic motivation and may result in undesirable achievement behaviours (Speirs Neumeister \& Finch, 2006). Powers and Wagner (1984) found that internal, ego-related attributions, such as effort and ability, were significantly positively correlated with achievement motivation ( $r=.31, p<.001)$, whereas external, causal attributions, such as context and luck, were not. Sideridis and Kafetsios (2008) found that perceptions of parental care, specifically care from mother and care from father, correlated negatively with fear of devaluing self $(r=-.30, p<.01 ; r$ $=-.35, p<.01)$, fear of uncertain future $(r=-.18, p<.01 ; r=-.23, p<.01)$ and fear of others losing interest $(r=-.28, p<.01 ; r=-.27, p<.01)$. A cluster analysis by Paulson, Marchant and Rothlisberg (1998) revealed that students who reported a positive view of parental involvement, such as perceived authoritative parenting, also reported the highest feelings of academic competence and school achievement. Another study (Spera, 2006) found a positive relationship between parental involvement practices, such as involvement in schoolwork, and interest in school for children $(r=.45, p<.001)$. One study which compared parental attachment with achievement motivation (Speirs, Neumeister \& Finch, 2006) found a significant correlation between insecure attachment and socially prescribed perfectionism, with $\beta=.52$ for the path from insecure attachment to socially prescribed perfectionism and $\beta=.32$ from socially prescribed perfectionism to avoidance motivation. Whereas self-oriented perfectionists set high standards for themselves, socially prescribed perfectionists tend to believe others set high standards which they are expected to meet (Hewitt \& Flett, 1991).

The purpose of the current study was to investigate the relationship between attachment and achievement motivation while addressing the relational gaps in the existing literature on influences on students' academic achievement. Spera (2006) focused on scholastic outcomes rather than the achievement motivation that could lead to these. Sideridis and Kafetsios (2008) hypothesized that fear of failure would mediate the relationship between parental attachment and stress. Paulson, et al. (1998) looked at perceptions of academic performance rather than achievement motivation. The goal of the present study was to assess the correlations between perceived parental attachment styles and achievement motivation independent from fear of failure. Previous studies have suggested that insecurely attached individuals may perform various tasks with the caregiver's affection as a motivator. Thus, it was expected that insecure attachment should be correlated with unhealthy achievement motivation (i.e., achievement motivation rooted in fear of failure). Specifically, it was hypothesized that (1) lower scores on perceived parental attachment dimensions shall be correlated with higher scores on performance-approach and performance-avoidance goals, (2) performance-approach and performance-avoidance goals will correlate positively with fear of failure, (3) higher scores on perceived parental attachment shall 
be correlated with higher scores on mastery, and that (4) mastery will correlate negatively with fear of failure. Although their significance is usually unappreciated by psychologists, religious variables often play a significant role in psychological processes (Spilka, Hood, Hunsberger, \& Gorsuch, 2003), hence data concerning religious affiliation and frequency of religious practice were collected as a matter of course in the event that they affect the hypothesized relationships.

\section{Method}

\section{Participants}

Fifty students (6 men, 44 women) with a mean age of 18.8 yr. were recruited online from the introductory psychology student pool at King's University College at the University of Western Ontario. Inclusion criteria included Canadian citizenship to try to reduce cultural differences that could affect the results. Students received up to $2.5 \%$ bonus marks for completing a related assignment. Demographic data indicated that 35 participants identified themselves as Christians, 12 identified themselves as belonging to no religion, and three identified themselves as belonging to some religion other than Christian, Islamic, or Judaic religions. Participants were designated as having "low frequency of religious practice" if they indicated that they did not belong to any religion or that they never practiced their religion, and "high-frequency of religious practice" if they indicated that they practiced their religion daily, weekly, or monthly. Of the 22 participants who fell in the low frequency of religious orientation category, 12 had no religious orientation, seven identified themselves as Christians, and three identified themselves as belonging to some religion other than Christian, Islamic, or Judaic religions. All 15 participants who were in the high-frequency of religious practice category were Christian. It should be also noted that King's University College is a Catholic liberal arts college.

\section{Measures}

Attachment.-Perceived parental attachment was measured using the Parental Attachment Questionnaire (Kenny, 1987), a 55-item self-report measure for individuals in late adolescence or early adulthood which assesses an individual's perceptions of parental relationships on three dimensions: Affective Quality of Relationship, Parental Facilitation of Independence, and Parents as Source of Support. Participants responded to each item by choosing a number on a 5-point scale (1: Not at all, to 5: Very much) that best described their parents, their relationship with their parents, and their feelings and experiences. Cronbach's alphas found in this study are as follows: .97 for men and .94 for women on Affective Quality of Relationship; .79 for males and .73 for females for Parental Facilitation of Independence; .85 for males and .76 for females for Parents as Source of Support.

Motivation.-Achievement motivation was measured by the Achievement Goals Questionnaire (Elliot \& Church, 1997) developed to assess mastery, performance-approach, and performance-avoidance goals. This questionnaire consists of 18 items in total with six items used to measure each of three goal constructs: (1) mastery (e.g., "I desire to completely master the 
material presented in this class"), (2) performance approach (e.g., "It is important to me to do better than other students"), and (3) performance avoidance (e.g., "I just want to avoid doing poorly in this class"). Participants indicate the extent to which they believe each item to be true of them, on a seven-point scale (1: Not at all like me, to 7: Very much like me). Responses are summed to form the three goal scales (Thrash \& Elliot, 2001). According to the present sample, Cronbach's alphas for the three achievement orientations are as follows: .97 for men and .76 for women for Performance-Approach; .50 for men and .87 for women for Mastery; .43 for men and .83 for women for Performance-Avoidance.

Motivation without fear of failure.-Achievement motivation free from fear of failure was characterized by low scores on the Performance Failure Appraisal Inventory (Conroy, 2003), which consists of 25 items measuring the strength of individuals' beliefs in five consequences of failing. Scores were provided for each of five consequences: (1) fear of experiencing shame and embarrassment; (2) fear of devaluing one's self-estimate; (3) fear of having an uncertain future; (4) fear of important others losing interest; and (5) fear of upsetting important others. Each response was measured on a 5-point scale (1: Do not believe at all, to 5: Believe $100 \%$ of the time). Scores were averaged to assess the individuals' general fear of failure, which represents the strength of one's belief that failure is associated with aversive consequences. All of the items on the Inventory are related to fear of failure, thus demonstrating good face validity. For the present sample the following Cronbach's alphas were obtained: .91 for men and .78 for women for fear of experiencing shame and embarassment; .63 for men and .79 for women for fear of devaluing one's self-estimate; . 37 for men and .50 for women for fear of having an uncertain future; .97 for men and .84 for women for fear of important others losing interest, and .82 for men and .81 for women for fear of upsetting important others. The overall alpha was .83 for men and .83 for women for the 25 items (Conroy, Willow, \& Metzler, 2002).

\section{Procedures}

Participants signed up online and were provided with dates, times, and locations from which they were instructed to choose a time slot for participation. In groups of approximately five, they attended the Psychology Laboratory at King's University College and were provided with a consent form and demographic questionnaire, which they were instructed to read and complete before beginning the tasks. After handing in the form and questionnaire, participants were given a package consisting of the Parental Attachment Questionnaire, Achievement Goals questionnaire, and the Performance Failure Appraisal Inventory. Participants had less than one hour to complete all three questionnaires. They were debriefed immediately following their completion of the questionnaires and were asked to complete a related assignment.

\section{Analysis}

Data were entered into an SPSS data file and correlation and regression analyses were performed to determine assess whether high or low perceived parental attachment was correlated with achievement motivation. 


\section{Results}

Participants' sex was examined for potential effects and no statistically significant differences between men and women were found on any of the measures. Thus, both men and women are included in the results.

Reliability and correlation analyses were performed to examine the means, standard deviations, and first-order relations among the participants' perceived parental attachment scores, achievement goals orientation scores, and fear of failure scores. No statistically significant correlations were found between perceived parental attachment and achievement orientation. However, a statistically significant negative relationship was found between Parents as Facilitators of Independence and General Fear of Failure. In addition, General Fear of Failure was statistically significantly correlated with both Performance-Approach and Performance-Avoidance (Table 1).

Table 1

Correlations of Selected Variables for the Entire Sample with Cronbach's Alphas For Scales

\begin{tabular}{|c|c|c|c|c|c|c|c|}
\hline & $\begin{array}{c}\text { Cronbach's } \\
\alpha\end{array}$ & 2 & 3 & 4 & 5 & 6 & 7 \\
\hline $\begin{array}{c}\text { 1.Affective Quality of } \\
\text { Relationship }\end{array}$ & .95 & $.62 \dagger$ & $.66 \dagger$ & -.06 & -.22 & .07 & -.24 \\
\hline $95 \% \mathrm{CI}$ & & $.41, .77$ & $.47, .79$ & & & & \\
\hline \begin{tabular}{|c|} 
2.Parents as Facilitators of \\
Independence
\end{tabular} & .86 & & $.31 *$ & -.12 & .04 & -.10 & $-.45 \dagger$ \\
\hline $95 \% \mathrm{CI}$ & & & $.34, .54$ & & & & $-.65,-.19$ \\
\hline $\begin{array}{c}\text { 3.Parents as Source of } \\
\text { Support }\end{array}$ & .77 & & & .09 & -.01 & .16 & -.04 \\
\hline 4.Performance-Approach & .83 & & & & -.12 & $.32 *$ & $.55 \dagger$ \\
\hline 95\%CI & & & & & & $.05, .55$ & $.32, .72$ \\
\hline 5.Mastery & .84 & & & & & -.08 & -.14 \\
\hline 6.Performance-Avoidance & .79 & & & & & & $.59 \dagger$ \\
\hline $95 \% \mathrm{CI}$ & & & & & & & $.37, .75$ \\
\hline 7.General Fear of Failure & .91 & & & & & & \\
\hline
\end{tabular}

${ }^{*} p<.05, \dagger p<.01$, two-tailed.

Given that the first-order analyses provided little support for the original hypotheses, the role of religiosity was explored in an effort to shed light on the data. Post hoc correlation analyses were performed on all the variables separately for high-frequency $(n=15)$ and low frequency $(n=22)$ religious practitioners. An effect of religious practice was observed: for low frequency of religious practice, a statistically significant negative relationship was found between Affective Quality of Relationships and General Fear of Failure $\left(r_{20}=-.45, p<.05\right.$; 95\%CI $\left.=-.73,-.04\right)$ and 
between Parents as Facilitators of Independence and General Fear of Failure, $\left(r_{20}=-.63, p<.01\right.$; $95 \% \mathrm{CI}=-.83,-.28$ ). For high-frequency religious practitioners, a significant positive relationship is found between Parents as Source of Support and Performance-Avoidance, $\left(r_{13}=.53, p<.05\right.$; $95 \% \mathrm{CI}=.02$, .82). A significant positive correlation was also found between General Fear of Failure and Performance-Avoidance Motivation for high-frequency religious practitioners, $\left(r_{13}=\right.$ $.67, p<.01 ; 95 \% \mathrm{CI}=.24, .88)$.

Additional post hoc correlational analyses were performed on Performance-Avoidance and each dimension of the Performance Failure Appraisal Inventory for high-frequency religious practitioners to identify which dimensions may influence the relationship between Parents as Source of Support and Performance-Avoidance. The analyses revealed that PerformanceAvoidance was correlated positively with Fear of Experiencing Shame and Embarrassment, $\left(r_{13}=\right.$ $.59, p<.05 ; 95 \% \mathrm{CI}=.11, .85)$, and Fear of Devaluing One's Self-estimate, $\left(r_{13}=.86, p<.01\right.$; $95 \% \mathrm{CI}=.62, .95){ }^{3}$

Due to their significance in the post hoc analyses, General Fear of Failure, Fear of Experiencing Shame and Embarrassment, and Fear of Devaluing One's Self-estimate were checked to assess whether they mediated the relationship between Parents as Source of Support and Performance-Avoidance Motivation for participants in the high-frequency of religious practice condition. The multiple linear regression analysis performed with Performance-Avoidance Motivation as the criterion variable and Parents as Source of Support and Fear of Devaluing One's Self-estimate as the predictor variables revealed a statistically non-significant beta for Parents as Source of Support $(\beta=.16, n s)$, but a statistically significant one for Fear of Devaluing One's Selfestimate $(\beta=.78, p<.01)$. The beta obtained for linear regression with Fear of Devaluing One's Self-estimate as the criterion and Parents as Source of Social Support as the predictor had a beta value of $\beta=.47(p<.10)$. Sobel's test for Fear of Devaluing One's Self-estimate as a mediator gave $S_{15}=1.78(p<.10$, two-tailed, see Fig. 1 (added after published version)).

\footnotetext{
${ }^{3}$ The Kolmogorov-Smirnov test for Performance-Avoidance was significant, but visual inspection showed that the scores are reasonably normally distributed. All other assumptions for the use of parametric tests for the data reported in this paper were met.
} 
Fig. 1: Path Analysis

Fear of Devaluing One's Self Estimate as Mediator between Parents as Source of Support and Perfomance-Avoidance Motivation in High Frequency Religious Practitioners

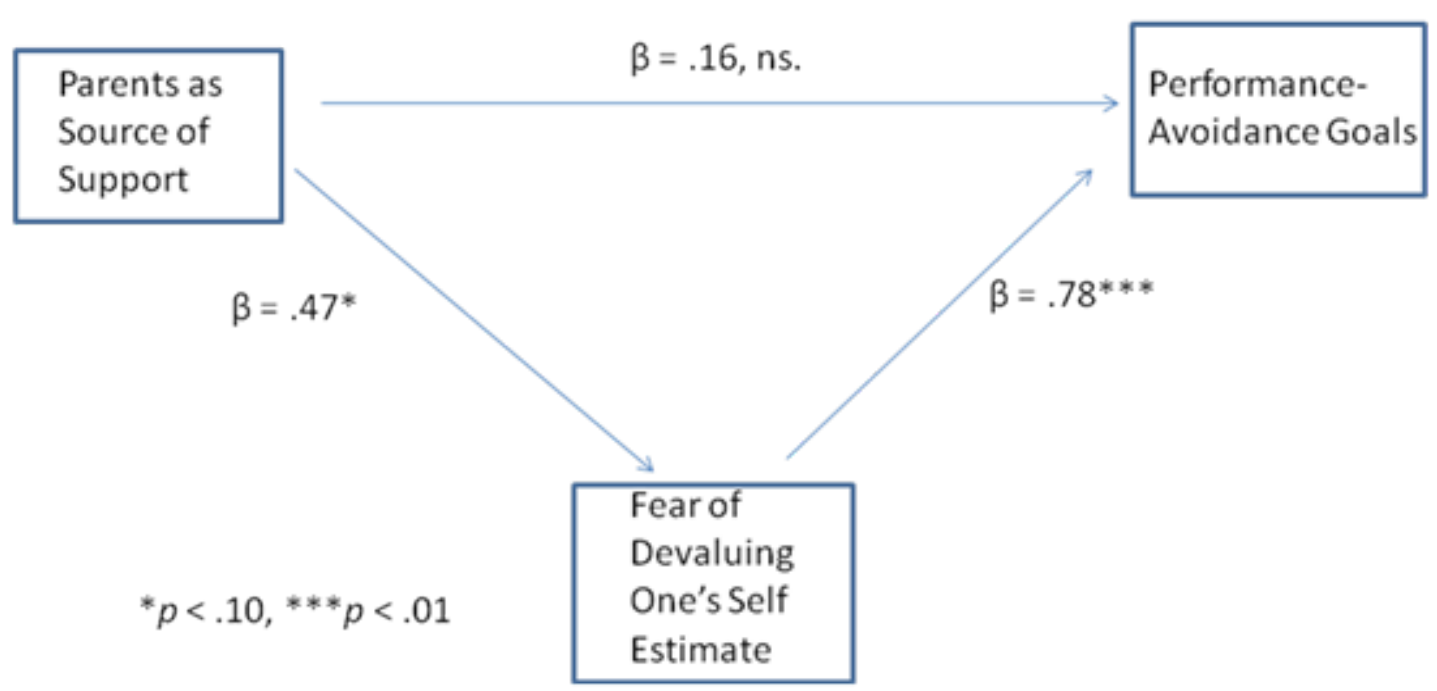

\section{Discussion}

The results provide partial support for the hypothesis that high parental attachment is related to the development of healthy achievement motivation. Ratings of parents as facilitators of independence correlated negatively with general fear of failure for the entire sample. It was also found that both performance-approach and performance-avoidance goals were concentrated with higher levels of fear of failure than the mastery goal. No dimension of the Parental Attachment Questionnaire statistically significantly predicted high or low scores on any of the achievement goals for the entire sample. However, an unexpected effect of religious practice was found: while high scores on the Affective Quality of Relationships and Parents as Facilitators of Independence dimensions of the Parental Attachment Questionnaire correlated with low General Fear of Failure in low frequency religious practitioners $(n=22)$, high scores on the Parents as a Source of Support dimension of the Parental Attachment Questionnaire correlated with high Performance-Avoidance Motivation in high-frequency religious practitioners $(n=15)$. Religious affiliations for the entire sample were checked and it was found that all high-frequency religious practitioners were Christian.

Research by Murk and Addleman (1992) suggests that religiosity has a significant influence over internal-external locus of control: according to their findings, Catholic students tended to score higher on External locus of control than did students belonging to other religious affiliations. In other words, "Catholics in this sample felt as if they had less control over situations than did subjects with other religious affiliations (Murk \& Addleman, 1992, p. 474). Although it remains unknown as to which sect of Christianity the high-frequency religious practitioners in the 
present study belong, it is likely that they are predominantly Catholic, as King's University College is a Catholic post-secondary institution.

In addition, while it is possible that high scores on the Parents as Source of Support dimension of the Parental Attachment Questionnaire appear to indicate a secure, healthy parental attachment, they may in fact suggest the contrary: the 13 items representing the Parents as Source of Support dimension of Kenny's Parental Attachment Questionnaire (1987) may reveal an unhealthy dependence of children on their parents. For example, Item 3 on the Parents as Source of Support dimension reads "In general, my parents protect me from danger and difficulty" (Kenny, 1987). The former item may suggest an unhealthy amount of dependence of the child on the parent during times of stress or danger. Similarly, Item 54 reads, "When I go to my parents for help, I feel confident that things will work out as long as I follow my parent's advice”, which may be suggestive of a lack of autonomy on behalf of the child when making decisions, due to an unhealthy amount of parental dependence.

If Catholics tend to have an externally-oriented locus of control, and if too much emotional support from parents may indicate unhealthy attachment, the results of the present regression analysis become less baffling than they initially appeared: an over-dependence on one's parents as a source of emotional support coupled with the belief that one has little control over his or her own achievement outcomes, could predict an unhealthy, avoidance approach motivation during any common, anxiety-provoking achievement situation.

The results of the present study advocate that it may be beneficial for parents and teachers to be more conscientious about their support styles and create environments that balance security with independence in order to prevent unhealthy patterns of attachment and achievement motivation. Future research could eliminate the limitations of the present study by including more male participants, more participants of different ethnic and religious backgrounds, and a larger sample. Follow-up studies could also investigate the role of religious affiliations and/or religious practice on attachment and achievement motivation in an attempt to maximize educational as well as social and work-related outcomes. It would also be important to consider additional suppressor variables that may mediate the relationship between attachment and achievement motivation. 
Attachment Theory, Achievement Motivation 10

\section{References}

Bowlby, J. (1982). Attachment and loss: Vol. 1. Attachment. New York: Basic Books. (Original work published 1969)

Conroy, D. E. (2003). The performance failure appraisal inventory: Brief user's manual. The Pennsylvania State University, 1, 1-9.

Conroy, D. E., Willow, J. P., \& Metzler, J. N. (2002). Multidimensional fear of failure measurement: The performance failure appraisal inventory. Journal of Applied Sport Psychology, 14, 76-90.

Dai, D., Moon, S., \& Feldhusen, J. (1998). Achievement motivation of gifted students. A social cognitive perspective. Educational Psychologist, 33, 45-63.

Elliot, A. J., \& Church, M. A. (1997). A hierarchal model of approach and avoidance achievement motivation. Journal of Personality and Social Psychology, 72, 218-232.

Hewitt, P. L., \& Flett, G. L. (1991). Perfectionism in the self and social contexts: Conceptualization, assessment, and association with psychopathology. Journal of Personality and Social Psychology, 60, 456-470.

Jagacinski, C. M., \& Duda, J. L. (2001). A comparative analysis of contemporary achievement goal orientation measures. Educational and Psychological Measurement, 61, 1013-1039.

Kenny, M.E. (1987). The extent and function of parental attachment among first-year college students. Journal of Youth and Adolescence, 16, 17-27.

Kirkpatrick, L. A. (1992). An attachment-theoretical approach to the psychology of religion. International Journal for the Psychology of Religion, 2, 3-28.

Murk, D. A. \& Addleman, J. A. (1992). Relations among moral reasoning, locus of control, and demographic variables among college students. Psychological Reports, 70, 467-476.

Paulson, S. E., Marchant, G. J., \& Rothlisberg, B. A. (1998). Early adolescents' perceptions of patterns of parenting, teaching, and school atmosphere: Implications for achievement. Journal of Early Adolescence, 18, 5-26.

Powers, S., \& Wagner, M. J. (1984). Attributions for school achievement of middle school students. Journal of Early Adolescence, 4, 215-222.

Reinert, D. F., \& Edwards, C. E. (2009). Attachment theory, childhood mistreatment, and religiosity. Psychology of Religion and Spirituality, 1, 25-34.

Speirs Neumeister, K. L., \& Finch, H. (2006). Perfectionism in high-ability students: Relationalprecursors and influences on achievement motivation. Gifted Child Quarterly, 50, 238- 251.

Sideridis, G. D., \& Kafetsios, K. (2008). Perceived parental bonding, fear of failure and stressduring class presentations. International Journal of Behavioral Development, 32, 119-130.

Spera, C. (2006). Adolescents’ perceptions of parental goals, practices, and styles in relations to their motivation and achievement. Journal of Early Adolescence, 26, 456-490.

Thrash, T. M., \& Elliot, A. J. (2001). Deliminating and integrating achievement motive and goal constructs. In A. Efklides, J. Kuhl, \& R. M. Sorrentino (Eds.), Trends and prospects in motivation research (pp. 3-21). Boston: Kluwer.

Vicary, A. M., \& Fraley, C. R. (2007). Choose your own adventure: Attachment dynamics in a simulated relationship. Personality and Social Psychology Bulletin, 33, 1279-12. 